\title{
Management of bilateral necrotizing bronchial dehiscence after a double lung transplantation
}

Swenn Maxence Krahenbuhl, MD, ${ }^{\mathrm{a}}$ Michel Gonzalez, MD, ${ }^{\mathrm{a}}$ John-David Aubert, MD, ${ }^{\mathrm{b}}$

Michael Tamm, MD, ${ }^{\mathrm{c}}$ Hans-Beat Ris, MD, ${ }^{\mathrm{a}}$ Thorsten Krueger, MD, ${ }^{\mathrm{a}}$ and Jean Yannis Perentes, MD, PhD, ${ }^{\mathrm{a}}$

Lausanne and Basel, Switzerland

\footnotetext{
From the Divisions of a Thoracic Surgery and ${ }^{b}$ Pneumonology, Centre Hospitalier Universitaire Vaudois, Lausanne, Switzerland; and ${ }^{\mathrm{c}}$ Division of Pneumonology, University Hospital of Basel, Basel, Switzerland. Disclosures: Authors have nothing to disclose with regard to commercial support.

Received for publication Nov 1, 2017; revisions received Feb 13, 2018; accepted for publication Feb 24, 2018; available ahead of print March 30, 2018.

Address for reprints: Jean Yannis Perentes, MD, PhD, Division of Thoracic Surgery, Centre Hospitalier Universitaire Vaudois, Rue du Bugnon 46, Lausanne 1011, Switzerland (E-mail: jean.perentes@chuv.ch).

J Thorac Cardiovasc Surg 2018;156:e29-31 $0022-5223 / \$ 36.00$

Copyright @ 2018 by The American Association for Thoracic Surgery https://doi.org/10.1016/j.jtcvs.2018.02.070
}

Anastomotic airway complications after lung transplantation affect up to $20 \%$ of patients and generally present as bronchial dehiscence or stenosis. ${ }^{1}$ Although bronchial complication classifications were described, there is no consensus regarding their management. ${ }^{2-4}$

We present a challenging case of complete bilateral bronchial dehiscence after lung transplantation in a patient with cystic fibrosis that we attributed to a Pseudomonas and Aspergillus necrotizing infection. We describe the medical and surgical management of this patient and his outcome.

\section{CASE REPORT}

A 27-year-old male patient with cystic fibrosis-related terminal respiratory insufficiency underwent bilateral lung transplantation. He was receiving azithromycin and

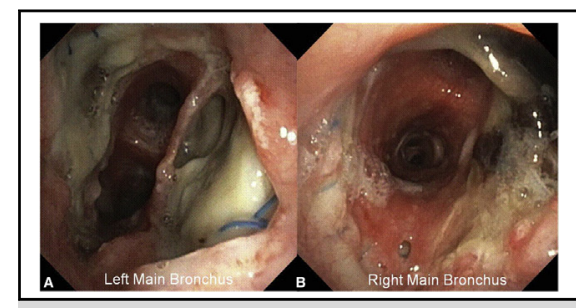

Bronchoscopic findings on day 13 after lung transplantation with (A) left-sided and (B) right-sided bronchial anastomosis necrosis and bronchial dehiscence.

\section{Central Message}

Bilateral bronchial dehiscence after lung transplant is successfully corrected by a bilateral posterolateral thoracotomy approach, allowing bronchial anastomosis reconfection and coverage by pediculed intercostal muscle flaps.

See Editorial Commentary page e33.

aztreonam antimicrobial treatment. His airway was colonized with multidrug-resistant Pseudomonas aeruginosa and Aspergillus. There were no pleural collections. The lungs of a suitable 28-year old neurologically dead donor were retrieved with standard antegrade and retrograde Perfadex (XVIVO Perfusion, Göteborg, Sweden) perfusion.

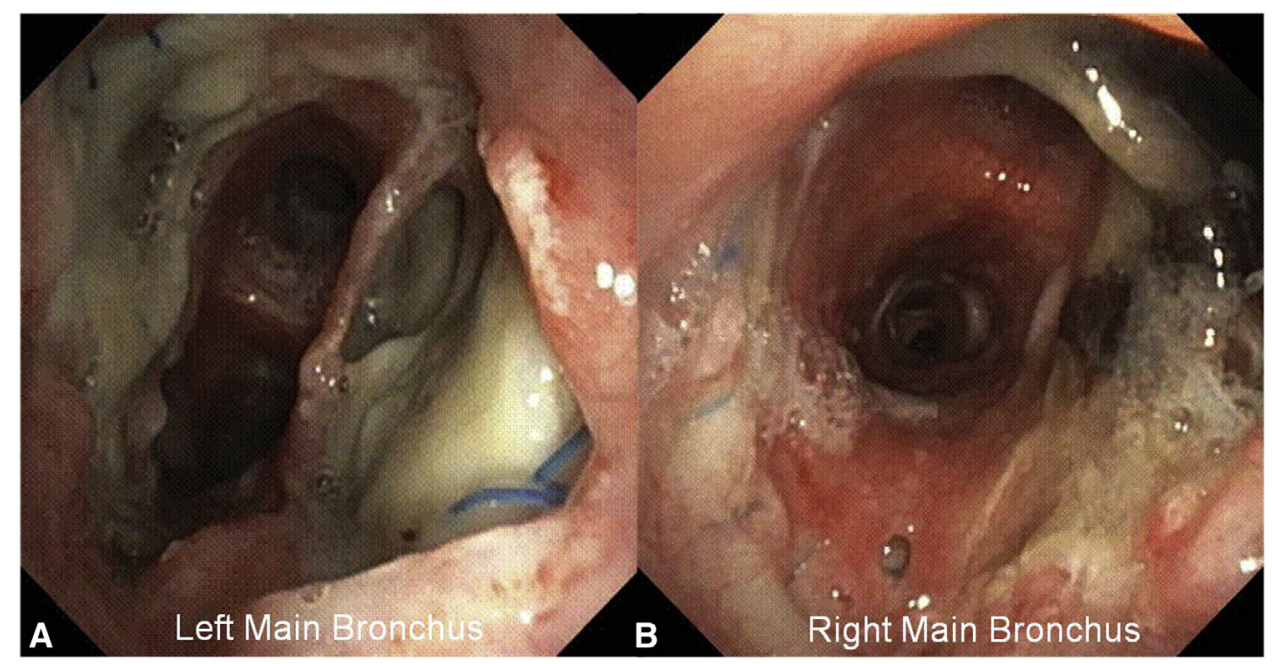

FIGURE 1. Bronchoscopic findings on day 13 after lung transplantation with (A) left-sided and (B) right-sided bronchial anastomosis necrosis and bronchial dehiscence. 


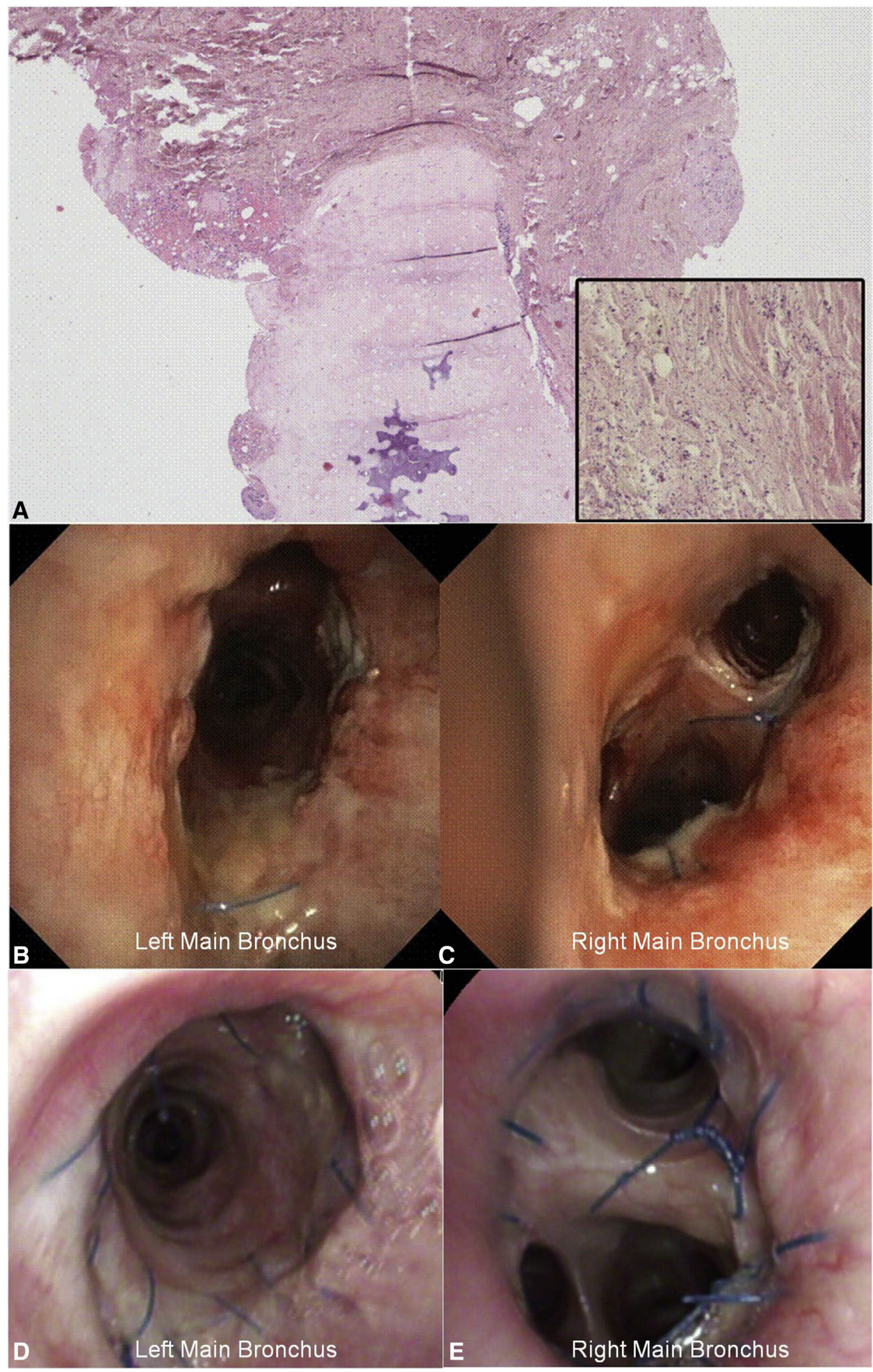

FIGURE 2. A, Histologic examination of the resected bronchial margins revealing a necrotic bronchial wall with residual cartilage (hematoxylin-eosin $20 \times$ ) and numerous Gram-positive bacteria (insert Gram stain $400 \times$ ). Bronchoscopic findings at 1 week (B: left side and C: right side) and at 1 year (D: left side and $\mathrm{E}$ : right side) after redo surgery with reconfection of both bronchial anastomosis and intercostal muscle flap coverage.

The lungs were implanted through a clamshell incision under central venoarterial extracorporeal membrane oxygenation (ECMO) support. The bronchus was anastomosed end-to-end with a running 4.0 polydioxanone suture on the membranous tied to two 3.0 polydioxanone corner stitches (at the membranous and cartilage junction, tied 
outside) and interrupted Prolene 4.0 sutures of the cartilage each placed around a ring of the donor and recipient. Ischemic times were 4 hours 10 minutes and 5 hours $40 \mathrm{mi}$ nutes for the right and left lungs, respectively. The ECMO was successfully weaned at the end of surgery. Cefepime, tobramycin, and voriconazole tri-therapy were administered postoperatively on the basis of the germ-resistance antibiograms. The patient was extubated on postoperative day 3. Antibiotics were switched to intravenous colistin and fosfomycin on postoperative day 6 because of Pseudomonas resistance on the perioperative bronchoalveolar lavage. On postoperative day 9, dyspnea developed in the patient. A chest computed tomography revealed bilateral lower lobe infiltrates associated with pleural effusions that we drained. Meropenem was added to the antibiotic regimen. On day 13 , air was visualized in the pericardium on the chest radiograph. A bronchoscopy revealed a bilateral anastomotic dehiscence with necrotic bronchial margins (Figure 1, $A$ and $B$ ). We performed an urgent surgical revision of both bronchial anastomoses via a sequential bilateral posterolateral thoracotomy. On both sides, we found necrotic peribronchial fatty tissue and necrosis of the bronchial anastomosis. A 2-mm circumferential resection of both bronchial margins was performed followed by an end-to-end reanastomosis using interrupted 4.0 Prolene sutures placed throughout the circumference of the bronchus under jet ventilation (left side) and peripheral jugulo-femoral venovenous ECMO support (right side because of ventilation difficulty of the left lung using jet ventilation). All sutures were tied on the outside of the bronchus except the anterior cartilaginous portion where 2 sutures were tied on the inside of the bronchial lumen (related to surgical field exposure blocked by the pulmonary artery). A pediculated intercostal muscle flap was then placed between the bronchus and the artery. The patient was extubated 2 days after the second surgery. Histologic examination of the bronchial margins revealed transmural necrosis and bacteria (Figure 2, A). The microbiological analysis grew Pseudomonas aeruginosa, Enterococcus faecalis, and Streptococcus anginosus/milleri. Accordingly, antibiotics were adapted and meropenem was replaced with piperacillin/tazobactam and maintained for 4 weeks. Control postoperative bronchoscopy at 1 week (Figure 2, $B$ and $C$ ) and 1 year (Figure 2, $D$ and $E)$ revealed satisfactory anastomotic healing. The patient was discharged from the hospital on day 36 after lung transplantation and is currently doing well 12 months after surgery.

\section{DISCUSSION}

Factors associated with airway complications after transplantation have been identified, including donor lung preservation, surgical technique, donor and recipient bacterial load/content, and immunosuppression. ${ }^{4}$ The relative ischemia of the bronchial anastomosis combined with the bacterial and fungal colonization is likely to cause necrotizing infections and dehiscence. A review of the prior microbiological reports of this patient revealed a multiresistant Pseudomonas identified 1 year before surgery. Although beta-lactam and aminoglycoside coverage are usually recommended in patients with cystic fibrosis, it might have been more judicious to cover the Pseudomonas more aggressively with intravenous colistin up-front.

According to the macroscopic, diameter, and suture (MDS) classification, the bronchial anastomotic dehiscence in our case corresponded to an M3a-D0-S3 stage, ${ }^{3}$ which should be managed aggressively. ${ }^{4}$ We chose a bilateral thoracotomy to redo both anastomoses and cover them with an intercostal muscle flap. Although venovenous ECMO was used only for the right anastomosis, we believe it could have been put up-front for safe bronchial tree repair surgery.

\section{CONCLUSIONS}

Complete bronchial dehiscence due to necrotizing infection after lung transplantation remains a challenging complication to manage. We report a successful approach for bronchial anastomosis reconstruction and the use of intercostals muscle flap coverage.

\section{References}

1. Santacruz JF, Mehta AC. Airway complications and management after lung transplantation: ischemia, dehiscence, and stenosis. Proc Am Thorac Soc. 2009;6: 79-93.

2. Dutau H, Vandemoortele T, Laroumagne S, Gomez C, Boussaud V, Cavailles A et al. A new endoscopic standardized grading system for macroscopic central airway complications following lung transplantation: the MDS classification. Eur J Cardiothorac Surg. 2014;45:e33-8.

3. Yserbyt J, Dooms C, Vos R, Dupont LJ, Van Raemdonck DE, Verleden GM. Anastomotic airway complications after lung transplantation: risk factors, treatment modalities and outcome-a single-centre experience. Eur J Cardiothorac Surg. 2016;49:e1-8

4. Alvarez A, Algar J, Santos F, Lama R, Aranda JL, Baamonde C, et al. Airway complications after lung transplantation: a review of 151 anastomoses. Eur J Cardiothorac Surg. 2001;19:381-7. 